\title{
Acute tryptophan depletion slows gastric emptying in females
}

\author{
Michiel A. van Nieuwenhoven ${ }^{1 *}$, Sabine D. M. Valks ${ }^{1}$, Sjacko Sobczak ${ }^{2}$, Willem J. Riedel ${ }^{2}$ and \\ Robert-Jan M. Brummer ${ }^{1}$ \\ ${ }^{1}$ Department of Gastroenterology, University Hospital Maastricht, Maastricht, The Netherlands \\ ${ }^{2}$ Department of Psychiatry and Neuropsychology, University Hospital Maastricht, Maastricht, The Netherlands
}

(Received 26 February 2003 - Revised 25 September 2003 - Accepted 3 November 2003)

\begin{abstract}
Serotonin (5-HT) is an important neurotransmitter involved in the brain-gut axis. It is possible to lower the 5-HT level in the body by means of a nutritional intervention using an amino acid mixture; the acute tryptophan depletion (ATD) method. We studied the effect of ATD on gastric emptying in healthy females, who received both ATD and placebo in a random order. Gastric emptying was measured using the $\left[{ }^{13} \mathrm{C}\right]$ octanoic acid breath test. The present data demonstrate significant differences in both gastric emptying and lag phase (Tlag) between the ATD and placebo experiment. Eight out of ten subjects showed a delayed gastric emptying in the ATD experiment. Both the gastric half-emptying time (T1/2) and the Tlag were significantly higher in the ATD experiment. T1/2 in the ATD experiment was 137.2 (range 76.2-634.8) $\mathrm{min}$; T1/2 for the placebo experiment was 98.5 (range 63.7-168.8) $\mathrm{min}(P=0.028)$. Tlag in the ATD experiment was 83.7 (range $45 \cdot 1-356 \cdot 2) \mathrm{min}$; Tlag for the placebo experiment was 56.9 (range $23 \cdot 2-101 \cdot 2) \mathrm{min}(P=0 \cdot 007)$. We conclude that lowering the 5-HT level in the body using the ATD method leads to a significantly delayed gastric emptying of a solid meal. Nutritional manipulation of the serotonergic system in healthy volunteers may lead to alterations in gastrointestinal motility.
\end{abstract}

Tryptophan depletion: Gastric emptying: Serotonin: Amino acids

Acute tryptophan depletion (ATD) is a method to temporarily reduce serotonin $(5-\mathrm{HT})$ synthesis by reducing the availability of its precursor tryptophan. This can be accomplished by the administration of an amino acid mixture lacking tryptophan, and may thus be considered more a nutritional rather than a pharmacological intervention. There is little doubt that the administration of an ATD mixture reduces 5-HT activity (Moore et al. 2000). In human subjects, a substantial reduction of brain 5-HT synthesis as well as decreased levels of tryptophan and 5-HT metabolites have been demonstrated following ATD (Nishizawa et al. 1997; Carpenter et al. 1998; Klaassen et al. 1999). It is probable that not only central 5-HT synthesis, but also peripheral 5-HT synthesis, is decreased following ATD.

ATD has been used over the past decade to investigate the role of the central 5-HT system in a variety of psychiatric conditions. It is reported in a number of studies that ATD reversed the effects of selective 5-HT re-uptake inhibitors and monoamine oxidase inhibitors in remitted patients with a history of depression or panic disorders. Details on studies using ATD in psychiatric research are described in review articles by Van der Does (2001) and Bell et al. (2001).

Delayed gastric emptying is reported in 30 to $82 \%$ of patients suffering from functional dyspepsia (Malagelada,
1991; Waldron et al. 1991; Maes et al. 1997). The treatment of delayed gastric emptying in functional dyspepsia comprises the use of prokinetic drugs acting on the serotonergic system. A commonly used drug is cisapride, a partial 5-HT4 receptor agonist (Veldhuyzen van Zanten et al. 2001). Prucalopride is a novel selective 5-HT4 agonist, which may also be useful to accelerate gastric emptying (Bouras et al. 2001).

It has been demonstrated that functional dyspepsia is frequently accompanied by an impaired accommodation of the proximal stomach following a meal (Tack et al. 1998). It appears that treatment with sumatriptan, a 5HT1 agonist, induces a relaxation of the gastric fundus in man and may therefore have therapeutic potential in the treatment of patients with functional dyspepsia. However, sumatriptan slows the gastric emptying rate (Houghton et al. 1992; Coulie et al. 1997) and a further delay in gastric emptying could be detrimental (i.e. increased nausea and epigastric symptoms) in patients already having a delayed gastric emptying. Other drugs acting on the serotonergic system comprise the anti-emetic drugs granisetron, ondansetron and alosetron. These drugs are 5-HT3 antagonists, acting both centrally and peripherally, and may be useful for the treatment of functional dyspepsia. However, these drugs have no effect on gastric emptying (Gore et al. 1990; Nielsen et al. 1990; Thumshirn et al. 2000). 
These studies demonstrate that the serotonergic system is involved in gastric motor and sensory function. Both the central and peripheral systems are probably involved. However, the precise role of 5-HT in the control of gastric function remains unclear due to the presence of multiple 5-HT receptors in the gastrointestinal tract. For instance, the prokinetic effect of 5-HT4 agonists suggests that a lack of 5-HT is involved in the pathophysiology of dysmotility-like functional dyspepsia. However, if this is the case, it is in contrast with the delayed gastric emptying, induced by a 5-HT1 agonist. In order to increase our understanding of the pathophysiology of functional dyspepsia, the aim of the present study was to investigate the effect of lowering the body 5-HT level by means of ATD on gastric emptying in healthy females.

\section{Materials and methods}

\section{Subjects}

Ten healthy female volunteers with a mean age of 22 (range 19-25) years participated in the present study. They were not pregnant and had no history of gastrointestinal or psychiatric disorders. They had no first-degree family members with psychiatric disorders. The subjects did not use medication, except for contraceptives. To avoid possible effects of the menstrual cycle on gastric motility, the subjects who did not use oral contraceptives were studied during the follicular phase of the menstrual cycle. Female subjects were studied because they are more sensitive to ATD, since the rate of 5-HT synthesis is lower in females than in males, at least in the brain (Nishizawa et al. 1997). The study was approved by the ethical committee of the Maastricht University Hospital.

\section{Design}

The study was conducted according to a placebo-controlled double-blind cross-over design. The treatments consisted of the oral administration of an amino acid mixture. The test mixture contained no tryptophan, and the placebo mixture was an amino acid mixture containing $3 \mathrm{~g}$ tryptophan. The treatment order was balanced over the two test days, which were separated by at least 1 week.

\section{Acute tryptophan depletion}

The amino acid mixtures were prepared by the department of pharmacy of the University Hospital. The mixtures differed slightly in $\mathrm{pH}$, osmolarity and energy content. However, it is improbable that these differences affected gastric emptying. The composition of the mixtures is displayed in Table 1 . The ATD mixture contained $1336 \mathrm{~kJ}$ and the placebo mixture $1387 \mathrm{~kJ}$. After an overnight fast, the subjects consumed the amino acid mixtures dissolved in $250 \mathrm{ml}$ water within a maximal time of $45 \mathrm{~min}$, using a noseclamp to avoid the unpleasant smell of the mixtures. Water, decaffeinated tea and peppermint were available to neutralise the unpleasant taste of the mixtures. From earlier studies in which this method was applied in fifty-six subjects, we know that this amino acid mixture leads to a
Table 1. Composition of the acute tryptophan depletion (ATD) and placebo mixture (g)

\begin{tabular}{lcc}
\hline Amino acid & ATD & Placebo \\
\hline L-Alanine & $4 \cdot 1$ & $4 \cdot 1$ \\
Glycine & $2 \cdot 4$ & $2 \cdot 4$ \\
L-Histidine & $2 \cdot 4$ & $2 \cdot 4$ \\
L-Lysine & $6 \cdot 7$ & $6 \cdot 7$ \\
L-Proline & $9 \cdot 2$ & $9 \cdot 2$ \\
L-Serine & $5 \cdot 2$ & $5 \cdot 2$ \\
L-Threonine & 4.9 & 4.9 \\
L-Arginine & $3 \cdot 7$ & $3 \cdot 7$ \\
L-Cysteine & $2 \cdot 0$ & $2 \cdot 0$ \\
L-Methionine & $2 \cdot 3$ & $2 \cdot 3$ \\
L-Isoleucine & 6 & 6 \\
L-Leucine & 13.5 & 13.5 \\
L-Phenylalanine & 4.3 & 4.3 \\
L-Tyrosine & $5 \cdot 2$ & $5 \cdot 2$ \\
L-Valine & 6.7 & 6.7 \\
L-Tryptophan & 0 & 3 \\
Total & $78 \cdot 6$ & 81.6 \\
\hline
\end{tabular}

plasma tryptophan depletion of 64.5 (SD 2.8) to 19.9 (SD 1.6) $\mu \mathrm{M}$, and the tryptophan:large neutral amino acids (LNAA) ratio decreases from 0.097 (SD 0.004) to 0.029 (SD 0.003), 4-7 h after ingestion of the ATD mixture (Riedel et al. 1999; Schmitt et al. 2000; Sobczak, 2002).

\section{Gastric emptying}

Gastric emptying was measured using the $\left[{ }^{13} \mathrm{C}\right]$ octanoic acid breath test. A tryptophan-free meal was administered $5 \mathrm{~h}$ after the start of the intake of the amino acid mixture. The meal consisted of two slices of protein-free bread with $10 \mathrm{~g}$ margarine and a spoon of treacle, and $300 \mathrm{ml}$ water. The meal was enriched with $100 \mu l\left[{ }^{1-13} \mathrm{C}\right]$ octanoic acid (99\%; Cambridge Isotope Laboratories, Andover, MA, USA), which was carefully mixed with the $10 \mathrm{~g}$ of margarine. The test meal was consumed in less than $10 \mathrm{~min}$. Breath samples for ${ }^{13} \mathrm{CO}_{2}$-enrichment analysis were drawn from a mixing chamber using vacutainer tubes at 15 min intervals during $4 \mathrm{~h}$. One breath sample was taken at least $1 \mathrm{~h}$ before the administration of the meal to determine background enrichment. The collected breath samples were analysed for ${ }^{13} \mathrm{C}$-isotopic enrichment of the expired $\mathrm{CO}_{2}$, using isotope ratio MS (MAT 252; Thermo Finnigan, San Jose, CA, USA). Mathematical analysis of the ${ }^{13} \mathrm{CO}_{2}$ data was performed according to Ghoos et al. (1993) and resulted in a gastric half-emptying time (T1/2) and lag phase (Tlag).

\section{Amino acids}

Plasma amino acids were measured before the ingestion of the amino acid mixture and $4 \mathrm{~h}$ after ingestion, using HPLC (Van Eijk et al. 1993). The tryptophan:LNAA ratio is calculated as follows: concentration of tryptophan/ (concentrations of tyrosine + leucine + phenylalanine + isoleucine + valine $)$.

\section{Statistics}

The Wilcoxon signed rank test was used to evaluate the differences in gastric emptying, plasma tryptophan 
concentrations and tryptophan:LNAA ratios. Data are presented as medians and ranges.

\section{Results}

Effects of acute tryptophan depletion on gastric emptying

Eight out of ten subjects showed a delayed gastric emptying in the ATD experiment compared with the placebo. In two subjects, there was no change of T1/2 in the ATD experiment compared with the placebo. However, one of these subjects vomited after ATD ingestion. In another subject, the Tlag did not change in the ATD experiment compared with the placebo while T1/2 increased in the ATD experiment. Both the T1/2 and the Tlag were significantly higher in the ATD experiment. In the ATD experiment the T1/2 was 137.2 (range $76 \cdot 2-634.8$ ) min and the Tlag was 83.7 (range $45 \cdot 1-356.2$ ) $\mathrm{min}$. In the placebo experiment the $\mathrm{T} 1 / 2$ was 98.5 (range 63.7-168.8) $\mathrm{min}$ and the Tlag was 56.9 (range $23.2-101.2$ ) $\mathrm{min}$. The $P$ values were $P=0.028$ (T1/2) and $P=0.007$ (Tlag) respectively (see Fig. 1).

\section{Effects of acute tryptophan depletion on plasma amino acids}

The plasma tryptophan data and the tryptophan:LNAA ratios are displayed in Figs. 2 and 3. ATD leads to a $59 \%$ decrease in plasma trytophan $(P=0.005)$ and a $93 \%$ decrease in the tryptophan:LNAA ratio $(P=0.005)$, compared with baseline. The placebo mixture leads to a $105 \%$ increase in tryptophan $(P=0.007)$ and a $21 \%$ decrease in the tryptophan:LNAA ratio $(P=0.06)$, compared with baseline.

\section{Discussion}

In the present study we have demonstrated that ATD, leading to a lowered plasma tryptophan concentration, which in turn leads to a lowered brain 5-HT concentration (Young et al. 1999), affects gastrointestinal motility. The ATD substantially decreased the gastric emptying rate. Previous

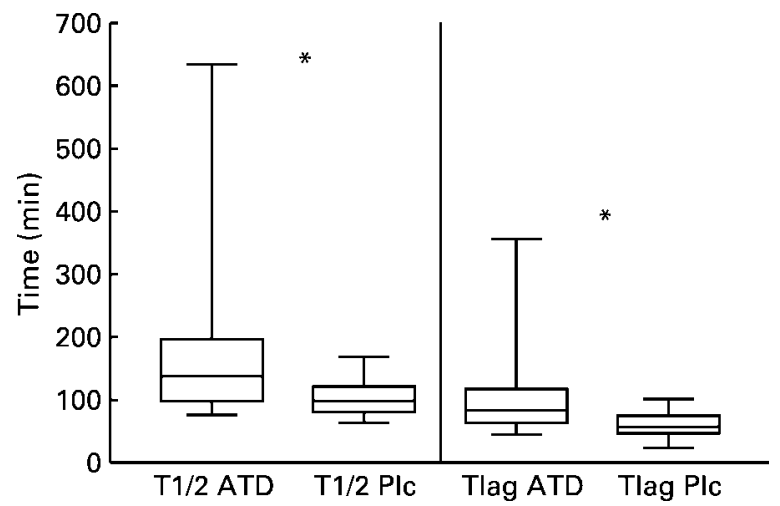

Fig. 1. The gastric emptying rates in the acute tryptophan depletion (ATD) and placebo (Plc) experiment $(n 10) .{ }^{*}$ The median values were significantly different for gastric half-emptying time (T1/2) $(P=0.028)$ and for lag phase (Tlag) $(P=0.007)$. The vertical bars represent ranges.

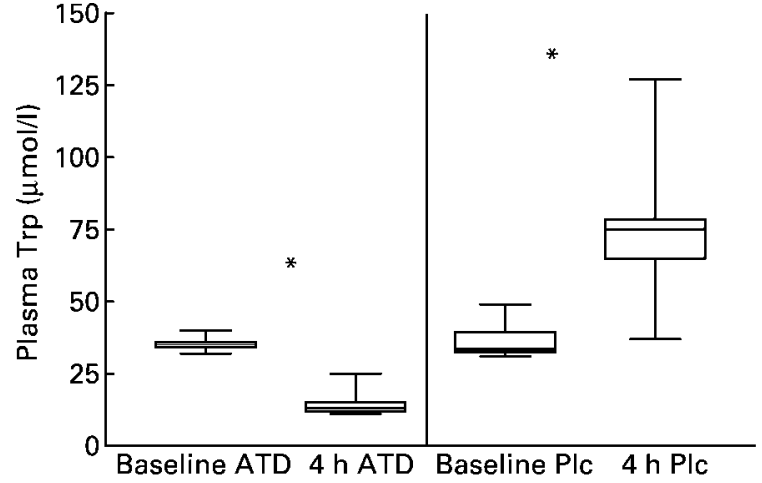

Fig. 2. Plasma tryptophan (Trp) values in the acute tryptophan depletion (ATD) and placebo (PIc) experiment ( $n$ 10). *The median values were significantly different in both experiments (ATD $P=0.005$; placebo $P=0.007$ ). The vertical bars represent ranges.

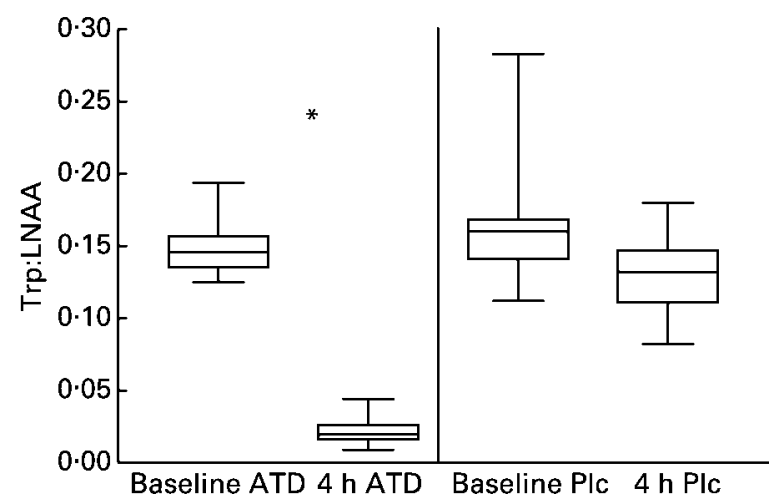

Fig. 3. Tryptophan:large neutral amino acid ratios (Trp:LNAA) in the ATD and placebo (Plc) experiment $(n 10)$. *The median values were significantly different in the ATD experiment $(P=0.005)$. Median values were not significantly different in the placebo experiment $(P=0.06)$. The vertical bars represent ranges.

studies showed that the ATD method leads to a 60-70\% decrease in plasma tryptophan levels in all subjects, 4-7 h after ingestion of the ATD mixture (Riedel et al. 1999; Schmitt et al. 2000; Sobczak, 2002). We confirm that in all subjects the plasma tryptophan values decreased as a result of ATD, with a mean decrease of $59 \%$, whereas the plasma tryptophan values in the placebo group were increased, due to the composition of the placebo mixture, which is not perfectly balanced for tryptophan. For the present study this may be beneficial since we studied the effect of alteration in tryptophan levels. We also observed an expected massive decrease in the tryptophan:LNAA ratio of $93 \%$, as a result of ATD.

The mechanism by which ATD influences gastric emptying is not known, but several mechanisms may be involved. At first, there is no reason to assume that the absence of tryptophan slows gastric emptying. In fact, the small number of publications on this issue point to an inhibition of gastric emptying by tryptophan, at least in the dog (Cooke \& Ward, 1976). At the level of the stomach, ATD probably leads to a lower 5-HT availability and hence to an impaired activation of the different 5-HT 
receptors such as the 5-HT1 and 5-HT4 receptors. This results in a slower gastric emptying as a net effect, suggesting that the effect of the activation of 5-HT4 receptors leading to an accelerated gastric emptying exceeds the effect of the activation of 5-HT1 receptors leading to a delayed gastric emptying and fundus relaxation.

At the level of the central nervous system, ATD leads to an impairment of long-term memory formation, and the reappearance of depressive symptoms in remitted depressed patients (Riedel et al. 1999). It may be possible that the delayed gastric emptying as observed in the present study is, at least partially, caused by central effects resulting from ATD. Circumstantial evidence for this hypothesis is provided by the fact that patients with functional gastrointestinal disorders, such as irritable bowel syndrome, but functional dyspepsia as well, are frequently treated with antidepressant drugs such as tricyclic antidepressants, and selective 5-HT re-uptake inhibitors such as fluoxetin and paroxetin. 5-HT re-uptake inhibitors increase the availability of 5-HT in the brain, and have become increasingly popular as a treatment in functional gastrointestinal disorders in the last few years. Treatment of these disorders with antidepressants appears to be effective in terms of symptom relief (Jackson et al. 2000). However, whether this improvement is independent of an effect of treatment on a depression or anxiety disorder, which are frequently present in patients with functional gastrointestinal disorders, has not yet been established. Other circumstantial evidence is provided by the fact that patients with functional dyspepsia display a lower vagal activity than healthy volunteers, which is associated with psychological factors (Haug et al. 1994). A decreased parasympathetic tone of the vagal nerve will result in antral hypomotility and an impaired accommodation of the proximal stomach, and hence, a slower gastric emptying of a solid meal. It may therefore be possible that ATD, leading to decreased central 5-HT availability, leads to a decreased vagal tone, which may also provide an explanation for the slow gastric emptying.

The results of the present study, together with the known involvement of decreased serotonergic action in functional bowel disorders with psychiatric co-morbidity, suggest that the delayed gastric emptying in functional dyspepsia may be associated with a relative lack of 5-HT availability at the level of the stomach, at the level of the brain, or both. Therefore, ATD may serve as a model for functional dyspepsia with respect to gastric emptying. The results also suggest that it may be useful to focus on treatment leading to an increased serotonergic activity. Based on the available literature, we suggest that activation of 5-HT4 receptors may be useful, since these receptors are involved in an acceleration of gastric emptying via intrinsic cholinergic neurons (Tonini et al. 1989).

Eight out of ten subjects showed a delayed gastric emptying in the ATD experiment. Two of them did not. One of them vomited $3 \mathrm{~h}$ before the experiment. Vomiting may be the result of the fact that the amino acid mixtures have an unpleasant smell and taste. For this reason the subjects were instructed to ingest the mixtures quickly, with a nose-clamp, and to have a peppermint. Changes in gastric motility due to nausea and vomiting could explain the absence of the delay in gastric emptying after ATD in these subjects. Feelings of nausea were reported in some subjects in both the ATD and the placebo group, and therefore it is not probable that the differences in gastric emptying are related to a degree of possible nausea.

In the present study we used the $\left[{ }^{13} \mathrm{C}\right]$ octanoic breath test. This is a well-established method to non-invasively measure gastric emptying using a stable ${ }^{13} \mathrm{C}$ isotope. This isotope can be measured in breath, and the enrichment of the breath with ${ }^{13} \mathrm{C}$ represents gastric emptying kinetics (Ghoos et al. 1993). Validation of this method against scintigraphy has been carried out using a standard meal containing a fried egg with bread and water. In the present study we could not use this test meal, since eggs contain tryptophan. For this reason we used a meal of protein-free bread with margarine and treacle. The $\left[{ }^{13} \mathrm{C}\right]$ octanoic acid was easily mixed with the margarine, and the gastric emptying data in the control experiment appeared to be normal. A possible systematic error does not influence the observed differences between the experiments.

In summary, we conclude that ATD leads to decreased gastric emptying. Based on the present results and the available literature we suggest that the effect of ATD on gastric emptying may be explained by either a peripheral effect, i.e. a decreased 5-HT4 receptor activation, a central effect, i.e. a decrease in vagal tone leading to a decreased motor activity of the stomach, resulting in a delayed gastric emptying, or a combination of both mechanisms. ATD may possibly be used to serve as a model for functional dyspepsia. Further physiological studies to establish the role of 5-HT within the brain-gut axis with respect to gastrointestinal motility are warranted.

\section{References}

Bell C, Abrams J \& Nutt D (2001) Tryptophan depletion and its implications for psychiatry. Br J Psych 178, 399-405.

Bouras EP, Camilleri M, Burton DD, Thomforde G, McKinzie S $\&$ Zinsmeister AR (2001) Prucalopride accelerates gastrointestinal and colonic transit in patients with constipation without a rectal evacuation disorder. Gastroenterology 120, 354-360.

Carpenter LL, Anderson GM, Pelton GH, Gudin JA, Kirwin PD, Price LH, Heninger GR \& McDougle CJ (1998) Tryptophan depletion during continuous CSF sampling in healthy human subjects. Neuropsychopharmacology 19, 26-35.

Cooke AR \& Ward WO (1976) Effect of tryptophan and its metabolites on gastric emptying of liquid meals in dogs. Proc Soc Exp Biol Med 152, 656-658.

Coulie B, Tack J, Maes B, Geypens B, De Roo M \& Janssens J (1997) Sumatriptan, a selective 5-HT1 receptor agonist, induces a lag phase for gastric emptying of liquids in humans. Am J Physiol 272, G902-G908.

Ghoos YF, Maes BD, Geypens BJ, Mys G, Hiele MI, Rutgeerts PJ \& Vantrappen G (1993) Measurement of gastric emptying rate of solids by means of a carbon-labeled octanoic acid breath test. Gastroenterology 104, 1640-1647.

Gore S, Gilmore IT, Haigh CG, Brownless SM, Stockdale H \& Morris AI (1990) Colonic transit in man is slowed by ondansetron (GR38032F), a selective 5-hydroxytryptamine receptor (type 3) antagonist. Aliment Pharmacol Ther 4, 139-144.

Haug TT, Svebak S, Hausken T, Wilhelmsen I, Berstad A \& Ursin H (1994) Low vagal activity as mediating mechanism for the relationship between personality factors and gastric 
symptoms in functional dyspepsia. Psychosom Med 56, $181-186$.

Houghton LA, Fowler P, Keene ON \& Read NW (1992) Effect of sumatriptan, a new selective 5HT1-like agonist, on liquid gastric emptying in man. Aliment Pharmacol Ther 6, 685-691.

Jackson JL, O'Malley PG, Tomkins G, Balden E, Santoro J \& Kroenke K (2000) Treatment of functional gastrointestinal disorders with antidepressant medications: a meta-analysis. Am J Med 108, 65-72.

Klaassen T, Riedel WJ, Deutz NE, van Someren A \& van Praag HM (1999) Specificity of the tryptophan depletion method. Psychopharmacology (Berlin) 141, 279-286.

Maes BD, Ghoos YF, Hiele MI \& Rutgeerts PJ (1997) Gastric emptying rate of solids in patients with nonulcer dyspepsia. Dig Dis Sci 42, 1158-1162.

Malagelada JR (1991) Gastrointestinal motor disturbances in functional dyspepsia. Scand J Gastroent 182, Suppl., 29-32.

Moore P, Landolt HP, Seifritz E, Clark C, Bhatti T, Kelsoe J, Rapaport M \& Gillin JC (2000) Clinical and physiological consequences of rapid tryptophan depletion. Neuropsychopharmacology 23, 601-622.

Nielsen OH, Hvid-Jacobsen K, Lund P \& Langoholz E (1990) Gastric emptying and subjective symptoms of nausea: lack of effects of a 5-hydroxytryptamine-3 antagonist ondansetron on gastric emptying in patients with gastric stasis syndrome. Digestion 46, 89-96.

Nishizawa S, Benkelfat C, Young SN, Leyton M, Mzengeza S, de Montigny C, Blier P \& Diksic M (1997) Differences between males and females in rates of serotonin synthesis in human brain. Proc Natl Acad Sci USA 94, 5308-5313.

Riedel WJ, Klaassen T, Deutz NE, van Someren A \& van Praag HM (1999) Tryptophan depletion in normal volunteers produces selective impairment in memory consolidation. Psychopharmacology (Berlin) 141, 362-369.
Schmitt JA, Jorissen BL, Sobczak S, van Boxtel MP, Hogervorst E, Deutz NE \& Riedel WJ (2000) Tryptophan depletion impairs memory consolidation but improves focussed attention in healthy young volunteers. J Psychopharmacol 14, 21-29.

Sobczak S (2002) Serotonin and Bipolar Disorders, PhD thesis, Maastricht University, The Netherlands.

Tack J, Piessevaux H, Coulie B, Caenepeel \& Janssens J (1998) Role of impaired gastric accommodation to a meal in functional dyspepsia. Gastroenterology 115, 1346-1352.

Thumshirn M, Coulie B, Camilleri M, Zinsmeister AR, Burton DD \& Van Dyke C (2000) Effects of alosetron on gastrointestinal transit time and rectal sensation in patients with irritable bowel syndrome. Aliment Pharmacol Ther 14, 869-878.

Tonini M, Galligan JJ \& North RA (1989) Effects of cisapride on cholinergic neurotransmission and propulsive motility in the guinea pig ileum. Gastroenterology 96, 1257-1264.

Van der Does AJ (2001) The effects of tryptophan depletion on mood and psychiatric symptoms. J Affect Disord 64, 107-119.

Van Eijk HM, Rooyakkers DR \& Deutz NE (1993) Rapid routine determination of amino acids in plasma by high-performance liquid chromatography with a 2-3 microns Spherisorb ODS II column. J Chromatogr 620, 143-148.

Veldhuyzen van Zanten SJ, Jones MJ, Verlinden M \& Talley NJ (2001) Efficacy of cisapride and domperidone in functional (nonulcer) dyspepsia: a meta-analysis. Am J Gastroenterol 96, 689-696.

Waldron B, Cullen PT, Kumar R, Smith D, Jankowski J, Hopwood D, Sutton D, Kennedy N \& Campbell FC (1991) Evidence for hypomotility in non-ulcer dyspepsia: a prospective multifactorial study. Gut 32, 246-251.

Young SN, Leyton M \& Benkelfat C (1999) Pet studies of serotonin synthesis in the human brain. Adv Exp Med Biol 467, $11-18$. 